\title{
RESPONSABILIDADE PRÉ-CONTRATUAL NAS RELAÇÕES DE EMPREGO: APLICAÇÃO DA TEORIA DA PERDA DE UMA CHANCE

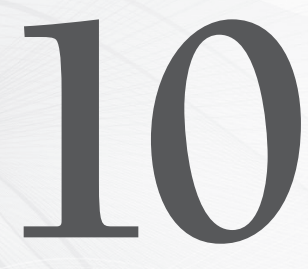

Contractual liability in pre-employment relations: application of the theory of loss of a chance

\section{Renato Lovato Neto}

Acadêmico do Curso de Direito da Universidade Estadual de Londrina - UEL.

\section{LouRIVAl José DE OLIVEIRA}

Doutor pela PUC-SP. Professor Associado do Curso de Direito da Universidade Estadual de Londrina - UEL. Professor e Coordenador do Curso de Graduação em Direito da Faculdade Paranaense e Professor do Curso de Mestrado em Direito da Universidade de Marilia.

Recebido em: 29.06.2012

Aprovado em: 15.08.2012

ÁreA do DIREITO: Trabalho

Resumo: A perda de uma chance se consolida como uma teoria construída com o fim de proteger a vítima que tem uma oportunidade de atingir um resultado vantajoso ou de evitar um prejuízo eliminado pela ação ou omissão do ofensor, visto que esta chance tem um valor jurídico de alta relevância. As relações de trabalho exigem a aplicação do princípio da boa-fé objetiva em todas as suas nuances e em cada uma
AвSTRACT: The loss of a chance established itself as a theory constructed in order to protect the victim that has an opportunity to achieve a favorable result or to avoid a loss eliminated by action or omission by the offender, as this chance has a legal value of great importance. Working relationships requires the application of the principle of objective good faith in all its nuances and each of its phases, as in 
de suas fases, seja nas negociações preliminares, na execução ou após a conclusão do contrato. 0 trabalhador, neste momento de tratativas, pode ser sujeito passivo de uma série de lesões decorrentes da deslealdade, omissão de informações, exigências desarrazoáveis e demais atuações abusivas do empregador. Neste ambiente, o trabalhador cria expectativas com relação a uma séria e real probabilidade de ser contrato ou de pactuar um acordo em condições mais vantajosas do que as que se consolidaram posteriormente, devido ao comportamento do empregador, e esta aniquilação da oportunidade de alcançar um resultado mais benéfico deve ser interpretada à luz da teoria da perda de uma chance. A perda de uma chance na fase pré-contratual no Direito do Trabalho advém da ação ou omissão do empregador em violação ao princípio da boa-fé, lesionando uma propriedade do trabalhador anterior à conduta do ofensor, não podendo este comportamento se efetivar mediante o argumento da autonomia das relações privadas e da liberdade negocial. Neste trabalho foi adotado o método dedutivo, com pesquisas doutrinárias e jurisprudenciais.

Palavras-chave: Responsabilidade pré-contratual - Negociações preliminares - Perda de uma chance - Relações de emprego. preliminary negotiations, execution or after the conclusion of the contract. The worker at this moment of negotiations, could be a victim of a series of injuries resulting from unfairness, missing information, and other disproportional requirements and others abusive actions of the employer. In this environment, the worker creates expectations of a real and serious and probability of being contract or agreeing a deal on more favorable terms than those which later were consolidated because of the conduct of the employer, and this aniquilation of the opportunity to achieve a result more beneficial must be interpreted in the light of the theory of loss of a chance. The loss of a chance in the pre-contract in Labour Law comes from the act or omission of the employer in violation of the good faith principle, injuring a worker ownership that precedes the conduct of the offender, and this behavior can not occur through the argument of autonomy of private relations and freedom of negotiation. In this study was adopted the deductive method, with doctrinal and jurisprudential research.

KeYwords: Pre-contractual responsibility Preliminary negotiations - Loss of a chance. Employment relationships.

SumÁrio: 1. Introdução - 2. Da teoria da perda de uma chance - 3. A responsabilidade pré-contratual no direito do trabalho - 4. Configuração da perda de uma chance na fase pré-contratual nas relações de emprego - 5. Conclusão - 6. Referências bibliográficas.

\section{INTRODUÇãO}

O trabalho objetiva a averiguação da aplicação da teoria da perda de uma chance em um momento nebuloso de toda relação contratual, qual seja, na fase das negociações preliminares. Ora, neste momento, não estão firmadas as diretrizes a serem seguidas na execução do contrato, se tratando tão somente de tratativas com o fim de, posteriormente, concretizar o acordo de vontades.

O artigo trata da fase pré-contratual no Direito do Trabalho, mais especificadamente nas relações de emprego, aonde o empregado sempre é hipossu- 
ficiente e a liberdade contratual não pode ser usufruída sem parâmetros. Esta etapa da formação do contrato pode ocasionar danos ao empregado, que não tem acesso a todas as informações e se submete à vontade e, muitas vezes, à arbitrariedade do empresário.

Com o fim de explorar o tema, será dissecada em uma curta análise a teoria da perda de uma chance e suas vertentes, averiguando qual a sua classificação mais apurada e qual a sua natureza jurídica, com a finalidade de apontar qual o instituto com a sistemática mais apropriada para compreensão de uma perda de chance no caso concreto nas relações de emprego.

Em capítulo próprio, a responsabilidade pré-contratual será abordada em toda a sua configuração, com base nos princípios do Direito Civil e como eles se relacionam com o Direito do Trabalho diante da peculiaridade das relações no seu âmago. Após estas elucidações, cabe estudar a perda de uma chance na fase pré-contratual das relações de trabalho, seus limites e sua interpretação, para demonstrar a aplicabilidade desta espécie de responsabilidade típica da doutrina civilista no campo das relações de emprego.

Para o fim proposto, o texto recorre ao método dedutivo e à pesquisa bibliográfica das obras de juristas renomados, bem como à análise de decisões proferidas por tribunais pátrios, visando a abordagem do tema sob o viés teórico e prático.

\section{DA TEORIA DA PERDA DE UMA CHANCE}

A teoria da perda de uma chance consiste em uma construção doutrinária e jurisprudencial com amplo desenvolvimento na Itália, França e Estados Unidos da América e que apenas começou a ser trabalhada em solo pátrio na década de 1990, com a primeira produção bibliográfica sobre o tema ocorrendo apenas em 1999, com a pioneira obra de Sérgio Novais Dias (1999, p. 15), que observa que "a escassa doutrina e pouquíssimos julgados brasileiros que reconhecem a responsabilidade civil (...) na perda de uma chance falham em não precisar em que situações (...) é responsável e, sobretudo, em que medida".

Com recentes monografias de Rafael Peteffi da Silva (2009, p. 14) e de Sérgio Savi (2009, p. 4), jogando luz sobre a matéria e atraindo atenção de juristas renomados, que passaram a tratar o assunto nos manuais de responsabilidade civil.

Contudo, ainda que a teoria comece a ser aplicada em diversos campos do Direito, há um longo caminho a ser percorrido, na medida em que muitas vezes a perda da chance tem uma interpretação equivocada, seja pela doutrina, seja na sua aplicação pelo Poder Judiciário, confundido as concepções sobre nexo causal e dano. 
A perda de uma chance ocorre quando há a eliminação, através da conduta culposa de outro sujeito, de uma oportunidade do indivíduo de aferir um benefício ou de evitar um prejuízo. Neste âmbito, a ação ou omissão do ofensor interrompe um processo aleatório iniciado antes de sua interferência e afasta a chance de alcançar aquele resultado favorável esperado, sem nunca haver a conclusão de que se, em caso de não ter ocorrido a interrupção da marcha causal, o resultado almejado de fato ocorreria.

Desta forma, há uma dúvida quanto ao alcance da vantagem esperada, se ela ocorreria ou não se não houvesse a conduta do sujeito ativo, o que desperta dúvidas da doutrina com relação à aplicação da teoria, pois, sob sua ótica, estas chances seriam apenas meras expectativas de, talvez, alcançar um resultado benéfico.

Entretanto, o nexo causal e o dano devem ser analisados sobre um prisma diferente, conforme a situação encontrada no caso concreto. A doutrina da perda de uma chance tradicionalmente a divide em casos "clássicos" e os ocorridos na seara médica (ou perda de uma chance de cura ou sobrevivência). A solução propostas por ambas divergem no sentido de se encontrar a segurança imprescindível para a condenação do ofensor a indenizar o dano.

Savi $(2009$, p. 5):

"É importante destacar, ainda, que há duas 'modalidades' de responsabilidade civil por perda de uma chance. 'A primeira utilizando um tipo de dano autônomo, representado pelas chances perdidas, e a segunda embasada na causalidade parcial que a conduta do réu representa em relação ao dano final." Normalmente, os casos de responsabilidade civil médica ou "responsabilidade civil por perda de uma chance de cura ou de sobrevivência', enquadram-se na segunda modalidade. (...) primeira modalidade, a chamada teoria 'clássica' da responsabilidade civil por perda de uma chance."

Silva (2009, p. 84) coloca que a divisão em dois segmentos da perda de uma chance atualmente é a mais aceita pela doutrina:

"Essa manifestação originou a corrente que, ainda hoje, é a mais aceita pela doutrina francesa, diferenciando a aplicação clássica da perda de uma chance, que significa o reconhecimento de um dano específico, da perda de uma chance em matéria médica."

Os autores que respaldam essa posição doutrinária fundam suas críticas na impossibilidade de se perquirirem as chances perdidas após o término do processo aleatório. Assim, a análise das chances perdidas não será mais uma suposição em direção ao futuro e a um evento aleatório cujo resultado nunca se saberá, mas uma análise de fatos já ocorridos, pois é absolutamente certo 
que o paciente restou inválido ou morto. O escopo dessa doutrina é estabelecer a diferença e "denunciar a confusão feita entre a reparação retrospectiva da perda de uma possibilidade pretérita e incerta de causar um dano e a reparação de uma perda para o futuro".

Nos casos clássicos, o entendimento doutrinário evoluiu no sentido de considerar a própria chance perdida como um dano autônomo e independente, diferente do denominado dano final (que seria a vantagem não alcançada), isto porque esta nunca será certa, mas apenas algo que jamais se poderá concluir que poderia ocorrer se a conduta do sujeito ativo não tivesse interferido na marcha causal. Aqui, a perda da chance consiste em um dano por si próprio, um dano emergente e não um lucro cessante (aonde há um juízo de quase certeza do quanto razoavelmente se deixou de lucrar diante do ato ilícito).

$\mathrm{Na}$ realidade, a perda de uma chance deve ser avaliada como um dano autônomo porque esta lesão é dotada de certeza, ou seja, é certo que a conduta do indivíduo aniquilou totalmente as oportunidades da vítima de atingir o fim proposto, mesmo que nunca se possa descobrir se ela poderia ou não ter chegado a ele. O que não é certo é se o efeito na expectativa seria concretizado se não ocorresse a intervenção na marcha causal, mas é real que esta conduta afastou o ofendido de qualquer possibilidade de o conseguir.

Noronha (2003, p. 666) analisa a perda de uma chance como um dano emergente autônomo nos seguintes termos:

“(...) apesar de ser aleatória a possibilidade de obter o benefício em expectativa, nestes casos existe um dano real, que é constituído pela própria chance perdida, isto é, pela oportunidade, que se dissipou, de obter no futuro a vantagem, ou de evitar o prejuízo que veio a acontecer" (grifo do autor).

Alguns autores inclusive entendem que a consideração da perda da chance como um dano autônomo já seria suficiente para a responsabilidade civil quando todas as chances forem eliminadas pela conduta, pois a situação é definitiva e não haveria mais como se chegar ao resultado esperado. Savi (2009, p. 12) recorre à Bocchiola e conceitua o sentido jurídico de chance como a probabilidade de obter um lucro ou evitar uma perda, o que a atribui um valor econômico e com conteúdo patrimonial:

“(...) Bocchiola afirma que (...) a chance aparece como "a não ocorrência de uma eventualidade favorável". Desta forma, a chance implicaria necessariamente em uma incógnita - um determinado evento poderia se produzir (...), mas a sua ocorrência não é passível de demonstração.

Nas palavras de Bocchiola: "É inútil esperar para saber se haverá ou não um prejuízo, porque o seu concretizar-se não depende absolutamente de qualquer 
acontecimento futuro e incerto. A situação é definitiva e não poderá ser modificada. Um determinado fato interrompeu o curso normal dos eventos, que poderia dar origem a uma fonte de lucro, de tal modo que não é mais possível descobrir se a chance teria ou não se realizado."

Se fosse possivel estabelecer, com certeza absoluta, que a chance teria logrado êxito, teríamos a prova da certeza do dano final (...), e, com isso, o ofensor seria condenado ao pagamento do valor do prêmio perdido e dos benefícios que o cliente teria com a vitória na demanda judicial. Por outro lado, se fosse possível demonstrar que a chance não se concretizaria, teríamos a certeza da inexistência do dano final e, assim, o ofensor estaria liberado da obrigação de indenizar" (grifo nosso).

De outra mão, a perda de uma chance na seara médica tem natureza jurídica diversa e requer a avaliação do nexo causal, quando então este será examinado como uma causalidade parcial, aonde a conduta do sujeito ativo pode ou não ter contribuído para um dano final efetivamente sofrido (morte ou invalidez permanente).

Destarte, nesta vertente há o emprego aos recursos oferecidos pela ciência das estatísticas e cálculos probabilísticos, aonde será avaliada qual a probabilidade do resultado benéfico ter sido realizado se o profissional tivesse agido de acordo com os mandamentos da literatura médica e da experiência (com base no avanço da ciência naquele momento e dos recursos a sua disposição). Assim, a participação do ofensor na materialização da lesão é calculada de acordo com a probabilidade de se ter alcançado a cura ou a sobrevivência se o médico atuasse de forma diversa, mais prudente e eficaz, averiguando no caso concreto quais as chances reais do paciente ter chegado ao estado que esperava.

Silva (2009, p. 58), que rebate o argumento de que não se pode firmar a responsabilidade do agente com base na causalidade parcial, oriunda de cálculos de probabilidade, alegando que:

"Pode-se assegurar, mesmo segundo os padrões ortodoxos, que o nexo causal já é determinado por meio de probabilidades. O que Jacques Boré e John Makdisi propõem é que a reparação seja concedida de acordo coma probabilidade efetiva e cientificamente provada.

Jacques Boré assevera que a utilização da causalidade parcial não seria algo antinômico com a aplicação ortodoxa da causalidade. Na realidade, todo processo etiológico é uma combinação entre lei causal e lei aleatória. Tal combinação pode ser encontrada na responsabilidade pela perda de uma chance, visto que o dano é formado por fatores conhecidos e desconhecidos (...).

Entretanto, a maioria dos autores considera inadequado que o direito reconheça um nexo de causalidade que possa ser posto à prova por fatores aleatórios e desconhecidos. 
Como resposta, Jacques Boré observa essa objeção, que é a base das críticas dirigidas contra a jurisprudência relativa à perda de uma chance, procede de uma restrição mental que encobre a presença irredutível do fator aleatório em todos os processos causais. Na realidade, não existe qualquer sistema etiológico no qual todos os fatores sejam conhecidos exaustivamente" (grifo nosso).

Apesar desta apreciação dicotômica da teoria da perda de uma chance, a proposta de divisão que aborda todas as hipóteses constitui na que se baseia no momento da interrupção do processo aleatório e se este chegou ou não ao seu final. Nos chamados casos clássicos, normalmente a conduta do ofensor aniquilou totalmente as chances do indivíduo de atingir um benefício ou evitar um mal, nunca se sabendo se poderia ou não ter chegado a este resultado, enquanto nos casos no ambiente médico, geralmente o dano final resta prontificado, isto é, o paciente faleceu ou não se curou, pois o processo aleatório chegou ao seu final e o sujeito ativo não atuou com todos os instrumentais ao seu alcance para afastar esta consequência lesiva, devendo nexo causal parcial ser calculado com base na probabilidade do médico de curar ou de evitar a morte se agisse de outra forma.

Silva (2009, p. 106) averba:

"Entretanto, constata-se que a ruptura entre casos "clássicos" de responsabilidade de perda de uma chance e casos de perda de uma chance na seara médica é um equívoco. (...)

Georges Durry (...) logrou demonstrar que existiam casos fora da seara médica que deveriam ser incluídos na mesma categoria. (...) casos como a quebra do dever de informar e a falha do sistema de segurança também necessitavam da utilização da causalidade parcial para tornar a teoria da perda das chances apta a operar.

De outro lado, Fraçois Chabas, mesmo concordando com o cerne da doutrina majoritária, acabou atacando o outro flanco da ruptura por esta propugnada. $\mathrm{O}$ autor demonstrou que, em alguns casos médicos, também se poderia vislumbrar a aplicação clássica da teoria da perda das chances, pois se estaria diante da utilização de um conceito específico de dano, tendo em vista que o processo aleatório em que se encontrava a vítima foi interrompido em momento anterior ao seu estágio derradeiro.

(...) entende-se que a correta sistematização atual da teoria da perda de uma chance encerra duas categorias. A primeira estaria embasada em um conceito específico e independente de dano. A segunda, por outro lado, estaria respaldada no conceito de causalidade parcial em relação ao dano final. (...)

A rigor, pretende-se propor aqui uma ruptura, porém não mais entre os casos "clássicos" e aqueles vinculados à seara médica. Também seria correto 
afirmar que todas as vezes que o processo aleatório em que se encontrava a vítima é interrompido, com a perda definitiva da vantagem esperada e a total aniquilação das chances da vítima, está-se diante de chances perdidas como dano específico e autônomo. Porém, quando o processo aleatório chegou até o final, como costuma acontecer na seara médica, a noção de causalidade parcial é chamada a depor. Neste último caso, a conduta do agente apenas retira algumas chances de a vítima auferir a vantagem esperada, fazendo com que esta ainda possa ser alcançada" (grifo do autor).

Por fim, a perda de uma chance possui natureza jurídica de dano emergente quando o processo aleatório foi totalmente interrompido e nunca se poderá saber se o resultado esperado poderia ser efetivado, e de nexo de causalidade parcial quando o ofensor eliminou apenas algumas chances do sujeito de atingir um benefício, podendo se aferir, com o recurso da probabilística, qual possibilidade do desfecho ter sido diferença conforme outro modo de agir. Esta dissecação de acordo com o processo aleatório é mais satisfatória, visto que há casos clássicos em que se deve recorrer ao nexo causal parcial e situações no âmbito da Medicina em que a perda da chance será considerada como um dano autônomo.

\section{A RESPONSABILIDADE PRÉ-CONTRATUAL NO DIREITO DO TRABALHO}

As relações de emprego possuem natureza jurídica de difícil constatação e que passou por um processo evolutivo quanto a sua compreensão, devido a sua característica de fenômeno jurídico relativamente novo. Delgado (2008, p. 309) pondera acerca destas fases do entendimento das relações de emprego e as divide em teorias contratuais tradicionais (do arrendamento, da compra e venda, do mandato e da sociedade), contratualista moderna e acontratualista (da relação de trabalho e a institucionalista):

"Inicialmente, preponderou a tendência civilista de subordinar a nova e emergente figura do Direito às figuras clássicas e tradicionais do contratualismo do Direito Civil (teorias contratualistas tradicionais) (...).

Em seguida, já no século XX, surge a tendência de se procurar romper com qualquer traço teórico de origem contratual. Para este fim construiu-se caminho próprio e distintivo de elaboração teórica, com nítido caráter de resposta e antítese às proporções civilistas anteriores (teorias da relação de trabalho e institucionalistas).

Finalmente, chega-se a uma síntese teórica mais equilibrada e complexa, hábil a apreender não só os elementos aproximativos, mas também os diferenciadores da relação de emprego perante o conjunto de relações e institutos 
próximos e perante o universo jurídico conceitual existente (teoria contratualista moderna).

A ideia de contrato, como se percebe, foi o ponto fulcral na atividade classificatória empreendida pelos juristas.

Para as vertentes tradicionais (ou originárias), a relação empregatícia teria caráter contratual, sendo naturalmente assimilável a alguma das figuras contratuais existentes no universo do Direito Civil.

Para a vertente contratualista moderna, a noção de contrato seria também explicativa da natureza jurídica da relação de emprego (de sua substância e posicionamento classificatório, portanto), embora fosse inviável reduzir a nova figura a qualquer dos tipos contratuais existentes no âmbito civilista conhecido.

Já para as vertentes acontratualistas (teorias institucionalista e da relação de trabalho), a nova figura empregatícia não teria, definitivamente, natureza jurídica contratual, constituindo fenômeno divorciado da noção de liberdade e vontade que são nucleares à ideia de contrato" (grifos do autor).

Apesar da diversidade de análises sobre a natureza jurídica, a assimilação mais apurada e convergente com as suas características se funda no posicionamento contratualista moderno, aonde há o afastamento das tentativas de enquadrar a relação de emprego em algum dos modelos apresentados pelo Direito Civil. Ora, esta típica relação do Direito do Trabalho apresenta peculiaridades que não podem ser suprimidas para serem encaixadas no âmbito das espécies de contrato existentes no direito das obrigações, tais como a subordinação (ou seja, o modo como ocorre a prestação de serviço), que destoam, por exemplo, dos contratos previstos no Código Civil.

Todavia, a relação de emprego tem inegável caráter contratual, palpável sob o prisma da conceituação de contrato (Dınız, 2008, p. 13):

"O contrato constitui uma espécie de negócio jurídico, de natureza bilateral ou plurilateral, dependendo, para a sua formação, do encontro da vontade das partes, por ser ato regulamentador de interesse privados. Deveras a essência do negócio jurídico é a autorregulamentação dos interesses particulares, reconhecida pela ordem jurídica, que lhe dá força criativa. Num contrato, as partes contratantes acordam que se devem conduzir de determinado modo, uma em face da outra, combinando seus interesses, constituindo, modificando ou extinguindo obrigações. O contrato repousa na ideia de um pressuposto de fato querido pelos contraentes e reconhecidos pela norma jurídica como base do efeito jurídico perseguido. Seu fundamento é a vontade humana, desde que atue conforme à ordem jurídica. (...) 
(...) contrato é o acordo de duas ou mais vontades, na conformidade da ordem jurídica, destinado a estabelecer uma regulamentação de interesses entre as partes, com o escopo de adquirir, modificar ou extinguir relações jurídicas de natureza patrimonial" (grifo da autora).

Assim sendo, a relação de emprego configura um contrato entre empregador e empregado, baseado na liberdade das partes, manifestada pela vontade, vertente basilar que a diverge dos trabalhos de servidão e dos escravos, situações anteriores à venda da mais valia que caracteriza o fenômeno estudado (Delgado, 2008, p. 314).

Não obstante, o elemento vontade nos contratos regidos pela Consolidação das Leis do Trabalho se encontra mitigado por um rol de direitos e disposições previstas no Dec.-lei 5.452/1943 e na Constituição Federal de 1988, no art. $7 .^{\circ}$, que elencam uma série de direitos mínimos do empregado, sobre os quais apenas poderão ser negociadas cláusulas que consistam em um plus ao subordinado, em face dos princípios protetor e da norma mais benéfica, isto é, há pouco espaço de baliza para a elaboração do acordo na relação de emprego - que muitas vezes se apresenta basicamente como um contrato de adesão, pré-formulado pelo empregador - em face das normativas das Convenções e Acordos Coletivos de Trabalho, da CLT e da Constituição Federal de 1988, reduzindo a manifestação volitiva ao aceite ou não pelas partes (isto porque, o possível empregado, como hipossuficiente, não se encontra em posição de fazer exigências e demandas na formulação do contrato).

Sobre a vontade nas relações contratuais no Direito do Trabalho, Delgado (2008, p. 314) disserta:

"De fato, na medida em que a liberdade é o elemento fundamental a distinguir a relação de emprego das demais formas de relação de trabalho, do período anterior ao século XIX (servidão, escravidão), surge a vontade como seu elemento constitutivo basilar.

A vontade, como se sabe, é a particularização da liberdade em uma relação jurídica concreta. Na relação de emprego, essa vontade (e liberdade), apresenta, é claro, limitações inquestionáveis. Afinal, (...) não se trata tanto da vontade dirigida à definição do conteúdo do vínculo contratado, embora mantenha-se como vontade para definir sobre a efetiva pactuação do referido vínculo.

Não obstante limitada a vontade - sob a ótica do emprego, é claro - sua simples configuração e convergência à vontade empresarial, no que tange à constituição do vínculo, lança no mundo jurídico, como contrato, o instrumento de conexão do trabalhador ao sistema produtivo."

Com estas considerações iniciais sobre a natureza jurídica da relação de emprego, na medida em que esta figura como contrato, e com a aplicação do 
princípio da subsidiariedade (art. 8. ${ }^{\circ}$, parágrafo único, da CLT), ocorre que este vínculo deve ser regulado pelo diploma civilista, no que não for contrário aos preceitos do Direito do Trabalho, visto que este é insuficiente para reger toda a sistemática contratual. Ora, a legislação trabalhista não trata da responsabilidade civil na fase pré-contratual no seu âmbito normativo e deve recorrer aos parâmetros do Código Civil para a solução da problemática.

No entanto, a lei civilista igualmente não aborda a fase pré-contratual dos contratos por escabrosa omissão do legislador, que deixou de fora do ordenamento jurídico as negociações preliminares, tão importantes para a consolidação do direito das obrigações, ao contrário do Código Civil português, que prevê em seu art. 227 que:

"1. Quem negocia com outrem para conclusão de um contrato deve, tanto nos preliminares como na formação dele, proceder segundo as regras da boa fé, sob pena de responder pelos danos que culposamente causar à outra parte. (...)" (grifo nosso).

Por outro lado, o Código Civil delineia um conjunto principiológico ímpar que rege as relações jurídicas em todas as suas fases, pois não se pode pretender que exista uma conduta da parte de uma forma antes do contrato e de outra absolutamente diferente no decorrer de sua execução.

$\mathrm{O}$ art. 422 do CC/2002 determina que "os contratantes são obrigados a guardar, assim na conclusão do contrato, como em sua execução, os princípios da probidade e boa-fé" (grifo nosso) e, embora preveja os princípios apenas para as fases de execução e pós-contratual, coloca os enunciados que devem pautar a atuação das partes nas negociações anteriores à concretização do contrato, porque, conforme já destacado, não se pode aferir que princípios diferentes norteiam etapas do mesmo processo (VICENTE, 2004, p. 37):

"Uma dúvida, em face do disposto no art. 422, prende-se com o âmbito dos princípios de probidade e boa-fé nele consignados. Valem esses apenas para a fase da conclusão do contrato - hoc sensu, a troca das declarações de vontade (proposta e aceitação) pelas quais se forma o contrato - ou também para as negociações que a antecedem (por vezes ditas preliminares do contrato ou tratativas), durante as quais se prepara o conteúdo daquele?

A dúvida resulta de o referido preceito apenas aludir expressamente à primeira dessas fases, omitindo qualquer referência à segunda (...)".

Supomos, no entanto, que terão de se considerar compreendidas no art. 422 do CC/2202 as negociações encetadas com vista à conclusão do contrato, sob pena de, em duas fases do iter contratual funcionalmente ligadas entre si, as partes ficarem submetidas a exigências ético-jurídicas divergentes. Semelhante contradição valorativa, desconforme com o princípio da unidade da ordem ju- 
rídica e o próprio espírito do preceito, não parece admissível. Também no Direito brasileiro a boa-fé abrange, por isso, a fase dos preliminares do contrato."

Azevedo (1996, p. 25), em trabalho pioneiro sobre a responsabilidade pré-contratual, escreve acerca do princípio da boa-fé:

"A boa-fé objetiva constitui, no campo contratual (...) norma que deve ser seguida nas várias fases das relações entre as partes; o pensamento, infelizmente, ainda muito difundido, de que somente a vontade das partes conduz o processo contratual, deve ser definitivamente afastado. É preciso que, na fase pré-contratual, os candidatos a contratantes ajam, nas negociações preliminares e na declaração da oferta, com lealdade recíproca, dando as informações necessárias, evitando criar expectativas que sabem destinadas ao fracasso, impedindo a revelação de dados obtidos em confiança, não realizando rupturas abruptas e inesperadas das conservações etc. Aos vários deveres dessa fase seguem-se deveres acessórios à obrigação principal na fase contratual (...). Em qualquer uma das fases contratuais, a cláusula geral da boa-fé, como norma de comportamento, cria, para as partes, deveres positivos e negativos; estão, entre os primeiros, os deveres de colaboração, inclusive de informação (...) e, entre os segundos, os deveres de lealdade, especialmente o de manter sigilo."

Com a determinação dos parâmetros principiológicos de todo o processo relacionado aos contratos, o estudioso (ViCENTE, 2004, p. 35) define:

"Assim, afirma-se que o Código consagrou o instituto conhecido por "responsabilidade pré-contratual", também dita responsabilidade por culpa in contrahendo ou culpa na formação dos contratos, isto é, a responsabilidade civil por danos decorrentes de atos ou omissões verificados no período que antecede a celebração do contrato.

(...)

Tal corrente foi iniciada pelo ilustre jurista alemão Rudolph Von Jhering, em ensaio publicado em 1861, no qual o autor defendeu que, nos preliminares do contrato, há entre os negociadores uma relação obrigacional integrada por deveres de conduta cuja violação faz incorrer o infrator na obrigação de indenizar os danos desse modo causados à outra parte."

A partir disto, despreende-se que (Silva; BezerRa, 2012, p. 6643):

“(...) pode-se perceber na responsabilidade decorrente das relações de trabalho diversas semelhanças com a responsabilidade civil, especialmente no tocante a configuração da responsabilidade pré e pós-contratual, haja vista que essas sempre têm como fundamento o art. 422 do CC/2002, que nesse particular é aplicado subsidiariamente nas relações de cunho laboral."

Ainda, a formulação e negociação pré-contratual deve visar, nas tratativas iniciais, o cumprimento da função social do contrato, nos termos do art. 421 
do CC/2002, o que limita a liberdade e a vontade, fatores elementares do acordo, que deve respeitar aquele elemento, sob pena de violar fundamentos da República Federativa do Brasil - por exemplo, os valores sociais do trabalho e da livre iniciativa - bem como dificultar o alcance de objetivos republicanos fundamentais - valendo citar a erradicação da pobreza e da marginalidade e a redução das desigualdades (dispostos nos arts. 1. ${ }^{\circ}$, IV, e 3. ${ }^{\circ}$, III, da CF/1988).

Entretanto, no Direito do Trabalho, a não contratação do trabalhador se situa dentro do direito potestativo e diretivo do empregador, quer dizer, ele assume os riscos da atividade empresarial, então deve se limitar aonde que começa a responsabilidade pré-contratual, quer dizer, a partir de que momento o trabalhador que não foi contratado tem o direito subjetivo de pleitear a indenização de danos porventura oriundos do encerramento das negociações preliminares.

Vicente (2004, p. 37), nesta direção, esclarece que:

"O rompimento das negociações corresponde, em princípio, ao exercício de um direito: o direito de não contratar, uma das faces da autonomia privada.

Contudo, segundo o art. 187 do Código Civil brasileiro, também comete ao ilícito o titular de um direito que, ao exercê-lo, excede manifestamente os limites impostos pelo seu fim econômico ou social, pela boa-fé ou pelos bons costumes."

"É a consagração da doutrina do abuso de direito, por força da qual a invocação da titularidade de um direito não retira ilicitude à violação de direito alheio, caso seja este irregularmente exercido.

Deve, a esta luz, ser tido como ilícito o rompimento de negociações, designadamente: nas hipóteses de recesso intencional, ou seja, nas situações em que uma das partes faça malograr intencionalmente negociações que normalmente conduziriam a um resultado positivo (...) e nas situações em que, tendo uma das partes criado à outra uma conviç̧ão razoável de que contrataria com ela, induzindo-a a realizar despesas com esse fim, rompe arbitrariamente as negociações, recusando-se a celebrar, dentro do prazo acordado, o contrato projetado. (...)

Em contrapartida, não incorre em violação dos deveres de boa-fé nas relações pré-contratuais aquele que advertir a contraparte, com a devida antecedência, de que a celebração do contrato constitui uma mera eventualidade e de por findas as relações pré-contratuais ao verificar a impossibilidade de concluí-lo" (grifo do autor).

$\mathrm{O}$ autor coloca, então, que a parte que não pretende concluir o acordo deve romper as tratativas tão logo que tem conhecimento deste fato, pois não deve procrastinar as negociações sem a finalidade de compactuar, na medida em que gera infundada esperança ao outro polo, que pode vir a efetuar despesas com base nisto. 
Por outro lado, a parte vitimizada não pode requerer a reparação de meras expectativas sem fundamento, quer dizer, se do caso concreto não se pode extrair que houve um aprofundamento da negociação do contrato de trabalho e que não ocorreu de fato um dano, não há que se falar em responsabilidade civil, aonde deve ser provado o prejuízo, o nexo causal, a culpa e a conduta. As esperanças vazias e interpretações equivocadas das tratativas não podem entrar no campo do dano indenizável, porque o intuito da reparação consiste na volta ao status anterior e não no enriquecimento ilícito fundamentado em criações mentais do empregado de que seria realmente contratado - conjunto fático que requer a atenção do juiz.

Silva (2012, p. 5194), de igual modo, insere o dano na fase pré-contratual no âmbito da responsabilidade civil extracontratual:

"Tanto na responsabilidade pré-contratual ou pós-contratual se enquadram na responsabilidade civil extracontratual, pois na primeira (pré) o vínculo jurídico não se formou, e na segunda (pós) o contrato já foi extinto.

Admite-se que a empresa, antes de contratar o empregado, obtenha informações sobre ambiente de trabalho e suas expectativas anteriores, exame de currículo, diplomas e certificados, conforme leciona o mestre Rodolfo Pamplona Filho (...).

Diante de tal afirmação, (...) o dano pré e o pós-contratual não decorrem de violação do contrato de trabalho e sim da ofensa a um dever de conduta, ou seja, ao princípio da boa-fé objetiva, inserido no art. 422 do CC/2002 (...)."

Cabe destacar que a jurista desvirtuou o princípio da boa-fé objetiva ao transformá-la no dever geral e absoluto de não lesar ao próximo, próprio da responsabilidade extracontratual, chegando a uma conclusão a partir dos pressupostos de outro instituto, o que tornam impróprias as suas considerações neste sentido, tanto que, posteriormente, a estudiosa determina que (Silva, 2012, p. 5195):

"Já as negociações preliminares são constituídas de fatos e tratativas em fase incipiente que objetivam fixar as condições e o objeto de um contrato ou um pré-contrato. (...)

Diante do exposto, conclui-se que a responsabilidade civil, nesse momento, resulta da quebra de um dever específico de boa-fé negocial pelo qual o dano daí emergente se encaixa na responsabilidade contratual."

Interessante é a posição do iminente jurista Dallegrave Neto (2004, p. 53), que afasta a caracterização da responsabilidade pré-contratual como extracontratual e a coloca no âmbito da sistemática contratual:

"Caio Mário da Silva Pereira sustenta que há dificuldade na determinação concreta da culpa in contrahendo, vez que para tanto se exige a conciliação de 
dois princípios: da liberdade contratual e da boa-fé no momento da condução das tratativas negociais. Assevera ainda que a culpa daí advinda é aquiliana e não contratual, vez que baseada na regra geral de que a ninguém é dado prejudicar outrem (neminem laedere), e, portanto, não se trata de violação de cláusula contratual, "pois que, nesta fase, ainda não existe contrato".

Coadunamos com a primeira parte da ilação, contudo ousamos discordar do saudoso jurista no que tange ao enquadramento da culpa in contrahendo na responsabilidade do tipo extracontratual. Ora, não se pode negar que quaisquer manifestações das partes ocorridas durante as tratativas são feitas na condição de pré-contratante e pré-contratado, o que levou Antonio Junqueira de Azevedo a concluir com acerto que a responsabilidade civil, nesse momento, resulta da quebra de um dever específico de boa-fé negocial, motivo pelo qual o dano daí emergente se enquadra na responsabilidade contratual.

Ademais, se é certo que no momento das tratativas o contrato não se aperfeiçoou em sua formação, também é correto inferir que no instante das preliminares já se verifica uma incipiente formação negocial" (grifos do autor).

O referido autor baseia esta concepção de que a responsabilidade pré-contratual não é extracontratual na ideia de que o rompimento das negociações preliminares, gerando dano ao empregado, não consiste em uma lesão ao dever geral e absoluto de não lesar, mas sim ao direito relativo aos sujeitos específicos vinculados pela relação jurídica com o fim de firmar um acordo de vontades. Ora, "os deveres pré-contratuais constituem imperativos de conduta destinados a satisfazer o interesse de sujeitos determinados (ou determináveis), o que (...) é o elemento que permite caracterizar distintamente as obrigações dos deveres jurídicos" (Ana Prata apud Dallegrave Neto, 2004, p. 61).

Assim, Silva (2012, p. 5194) e Vicente (2004, p. 37) ao situarem o dano na fase pré-contratual no abuso de direito, o colocaram na esfera da responsabilidade extracontratual, nas disposições dos arts. 186 e 187 do CC/2002, que determinam o dever geral de não lesionar a outrem, o que impossibilitaria o emprego dos princípios contratuais da boa-fé objetiva e da probidade previstos no art. 422 do CC/2002, sendo a conduta mais apurada e acertada a seguida por Dallegrave Neto (2004, p. 58), abarcando as negociações preliminares no alcance da responsabilidade contratual.

Azevedo (1996, p. 24), após analisar o fundamento da responsabilidade pré-contratual, conclui que:

"Pessoalmente, tendo em vista nossa ideia de que o contrato é um processo (uma sucessão de 'tempos', como ocorre com o próprio negócio jurídico), que vai, desde a fase pré-contratual, passando à fase contratual, distribuída em três fases menores (conclusão do contrato, eficácia do contrato e execução/adim- 
plemento do contrato), e indo até a fase pós-contratual, todas subordinadas à boa-fé objetiva, pensamos que, embora surgindo de ato ilícito, a responsabilidade pré-contratual, por se tratar de descumprimento de deveres específicos, gerados pela boa-fé objetiva, deva se submeter ao tratamento da responsabilidade contratual (...)" (grifo nosso).

Portanto, diante da amplitude de hipóteses que podem resultar em danos ao trabalhador no momento em que está negociando com o empregador um contrato de emprego, há a exigência do mútuo tratamento com respeito e exposição mais transparente o possível das reais intenções em efetivar aquele acordo, conforme a colocação de Silva (2012, p. 5197):

“(...) a esfera das negociações preliminares que pretendem a celebração do contrato de trabalho é evidenciada, principalmente no momento da entrevista. Sendo assim, eventual dano decorrente desse momento envolverá agente e vítima na condição jurídica de trabalhador e empresa-empregadora, violando-se o princípio da boa-fé não como um direito geral e absoluto, mas como um direito relativo aos pré-contratantes. (...)

(...) não é somente a frustração injustificada que gera dano pré-contratual, mas também a violação de deveres colaterais de comportamento (...)."

A hipossuficiência do trabalhador pressupõe uma conduta do empregador de consideração desta fragilidade, informando sobre as reais chances do indivíduo em fazer parte do quadro de empregados da empresa, não podendo sustentar e fomentar falsas expectativas de que ele será contratado, devendo, desde o início das negociações, prestar esclarecimentos sobre todas as condições em que o serviço será exercido e as cláusulas daquele acordo, permitindo apenas a limitação destes avisos com relação à conveniência do contrato - pois, por óbvio, não é o empregador que deverá mostrar para o indivíduo que há outras oportunidades melhores que a oferecida por ele, nos termos do entendimento de Vicente (2004, p. 38):

"Algum grau de malícia tem de ser tolerado nas negociações pré-contratuais. Tal deve, a nosso ver, coincidir com o chamado dolus bônus, isto é, na expressão do art. 253, n. 2, do Código Civil português, as sugestões ou artifícios usuais, considerados legítimos segundo as concepções dominantes no comércio jurídico e a dissimulação do erro, quando nenhum dever de elucidar o declarante resulte da lei, de estipulação negocial ou daquelas concepções."

Não obstante, a astúcia do empregador não pode ultrapassar os limites da razoabilidade em face da posição do trabalhador como mais fraco e, na maioria das vezes, com reduzido grau de conhecimento, devendo o magistrado analisar, no caso concreto sob sua análise, se as partes agiram de acordo com o princípio da boa-fé, que abarca todos os elementos consistentes na probida- 
de, informação, lealdade, confidencialidade, colaboração e proteção, além de cumprir com a função social do contrato, com o fim de efetivar os objetivos e princípios dispostos na Constituição Federal de 1988.

\section{Configuração da Perda de uma Chance na FASE pré-CONTRATUAL NAS RELAÇÕES DE EMPREGO}

A perda de uma chance no Direito do Trabalho encontra campo fértil, porém que deve ser explorado as devidas precauções diante da sistemática e principiologia própria, bem como das peculiaridades da relação de emprego. Nesta seara, cabe indagar se o empregado teria o direito de pleitear no Judiciário a perda da oportunidade por responsabilidade do empregador de alcançar um estado que consiste em uma melhora com relação ao status anterior, como, por exemplo, uma promoção ou a contratação do trabalhador, ou se isto estaria no âmbito do poder diretivo do empresário, que corre o risco da atividade.

O objetivo deste trabalho exige que a análise se atenha à perda de uma chance na fase pré-contratual, o que leva ao questionamento de Vicente (2004, p. 35) se o empregado “(...) pode (...) reclamar indenização por ter perdido a oportunidade de celebrar o mesmo contrato com um terceiro" ou, ainda, se a expectativa de ser contratado foi frustrada por culpa do empregador, se caberia alguma reparação com relação ao emprego e à remuneração que deixou de receber.

Inicialmente, vale transcrever trecho de obra de Noronha (2003, p. 668), que, apesar de extenso, resume a sua concepção sobre a teoria objeto do presente estudo, dividindo em quatro modalidades a partir de duas vertentes iniciais com base no processo aleatório - se este chegou ou não ao dano final -, chegando à perda de uma chance de obter uma vantagem futura (de realizar um benefício em expectativa ou de evitar um prejuízo futuro) e a de frustração da chance de evitar um dano efetivamente acontecido (perda da chance de evitar que outrem sofresse um prejuízo e a perda de uma chance por falta de informação):

"A primeira e mais importante dessas modalidades diz respeito às hipóteses que designaremos de perda da chance de obter uma vantagem futura, hipóteses que na doutrina francesa são conhecidas também como a perda de chance clássica (...). São hipóteses em que, devido a um fato antijurídico passado, fica frustrada a possibilidade de obter uma vantagem que era esperada no futuro, ou fica frustrada a possibilidade de evitar um prejuízo futuro. Como se vê, esta categoria abrange duas situações distintas, que vão constituir duas submodalidades dela: a perda da chance de realizar um benefício em expectativa, de um lado, e a perda da chance de evitar um prejuízo futuro, de outro. 
Numa e noutra submodalidade, como estamos perante hipóteses em que se invocam eventos que ocorreriam no futuro, se não fosse o fato antijurídico registrado, será necessário não só que se demonstre a probabilidade de que tais eventos viriam a ocorrer, como também que se evidencie que eles ainda são consequência adequada do fato antijurídico. (...)

Nessas duas submodalidades, a frustração da chance de obter a vantagem prevista surge porque o fato antijurídico interrompe um processo que estava em curso, mas em circunstâncias em que fica impossível afirmar que, sem a interrupção, o resultado em expectativa aconteceria necessariamente.

As outras duas modalidades de perda de chance acima referidas (a perda da chance de evitar que outrem sofresse um prejuízo e a perda de uma chance por falta de informação) dizem respeito a hipóteses em que os elementos que se projetam no futuro dizem respeito ao cômputo do grau de probabilidade, que porventura houvesse, de evitar um prejuízo que efetivamente atingiu uma pessoa (...), um dano presente. Ambas são modalidades que se diferenciam da perda de chance clássica pelo fato de esta dizer respeito a danos futuros (...).

Das duas modalidades que são de frustração da chance de evitar um dano efetivamente acontecido, a primeira é constituída pelos casos em que o indigitado responsável podia e devia ter evitado a ocorrência do dano, caso tivesse praticado um fato diverso daquele que lhe é imputado. Nela, como na perda de chance clássica, também havia um processo em curso, mas agora este é danoso e chegou ao seu final, tendo efetivamente causado o dano receado. A questão que aqui se põe é saber se tal dano (dano presente) poderia e deveria ter sido evitado, isto é, se o indigitado responsável poderia e deveria ter interrompido o processo danoso em curso. Para estes casos falaremos em perda da chance de evitar que outrem sofresse um dano efetivamente ocorrido (isto é, um dano presente).

A segunda modalidade relativa a danos presentes, em que falaremos $\mathrm{em}$ perda de uma chance por falta de informação, diz respeito à frustração da oportunidade de tomar uma decisão esclarecida, devido a ter havido quebra de uma dever de informar, que recaía sobre outra pessoa. Acontece quando alguém sofre determinado dano por não ter tomado a melhor decisão, que estaria ao seu alcance se outra pessoa tivesse cumprido o dever, que incidia sobre ela, de informar ou aconselhar. São casos em que uma decisão mais esclarecida, a ser tomada pelo próprio lesado, poderia eliminar o risco de este sofrer o dano, ou pelo menos poderia reduzi-lo" (grifos do autor).

Na perda de uma chance, não há a indenização de esperanças aleatórias de um resultado favorável, mas sim uma probabilidade razoável de que o trabalhador conseguiria atingir o esperado e que a conduta do ofensor o afastou de qualquer possibilidade de conquistá-lo. Neste sentido, o dano deve advir de 
uma possibilidade real e séria de contratação, além do efetivo prejuízo, conforme destacam Silva \& Bezerra (2012, p. 6648):

"Evidente que a prova nesses casos geralmente é bastante difícil, ante a apenas expectativa com relação à celebração do contrato. Contudo, restando demonstrada a real possibilidade da contratação e o prejuízo decorrente da não ocorrência da mesma, como por exemplo, a perda de outra vaga de emprego, o fato torna-se passível de reparação na modalidade pré-contratual."

Nas relações de emprego, poderão ocorrer tanto hipóteses em que o dano final de fato se realizou ou situações em que a vítima teve, pela conduta do empregador, a eliminação de todas as oportunidades de alcançar um benefício ou afastar um prejuízo.

A título de exemplificação, o trabalhador que tem uma grande probabilidade de ser contratado devido ao seu currículo (tempo de serviço, qualificações, entre outros) e é chamado para uma entrevista aonde todos os outros que foram convidados foram contratados, mas tem esta oportunidade mitigada porque o empregador agiu de forma discriminatória, empregando algum meio tipificado na Lei 9.029/1995, e utilizou este fator para a escolha de outro candidato, que evidentemente era menos gabaritado do que ele. O indivíduo teve todo o seu histórico analisado, tinha uma real e séria chance de ser contratado, mas foi afastado com base em um critério discriminatório que, além do dano moral, dará direito à responsabilidade por perda de uma chance, pois o entendimento do empregador eliminou toda e qualquer chance da efetivação do acordo, devendo aqui a perda de uma chance ser considerada como um dano em si - porque o processo aleatório foi totalmente interrompido.

As hipóteses em que o processo aleatório foi até o seu fim e o dano final de fato ocorreu exigem condições mais raras para a sua configuração, pois esta marcha causal está, em grande parte, sob o domínio do empregador, que guia todo o processo seletivo na fase pré-contratual e, no momento em que ele tem alguma conduta que o faz compreender que o indivíduo não será contratado, elimina toda e qualquer chance da vítima. Porém, pode ocorrer de ter uma fase de análise de currículo e de entrevista, por exemplo, e esta não ser conduzida de forma leal, com o entrevistador omitindo dados importantes ou induzindo o trabalhador a erros, diminuindo a oportunidade do trabalhador que tem uma probabilidade séria e real de ser contratado, mas que, no resultado final desta seleção, o empregador decide não o contratar devido à entrevista mal sucedida.

Nestas circunstâncias, o processo aleatório teve uma interrupção, mas continuou até o seu fim, com o desfecho negativo para o trabalhador, que teve uma parcela de suas chances eliminada pela conduta do ofensor, quando então o nexo causal parcial será calculado em cima da probabilidade dele ser con- 
tratado se a entrevista ocorresse de forma mais leal - esta possibilidade pode ser aferida pelo magistrado em pesquisa no campo de trabalho com base em outros processos seletivos realizados pela empresa ou até pela análise do currículo do empregado e da vaga na empresa.

Esta espécie de perda de uma chance é colocada por Fernando Noronha (2003, p. 685) como a aniquilação da oportunidade por falta de informação quando ocorre a violação de deveres de informar, que se estabelece:

"Quando (...) levar outra pessoa a tomar uma decisão que depois verifica não ter sido a melhor, ou quando simplesmente não for dada a esta pessoa a possibilidade de se manifestar, se depois vierem a acontecer danos que poderiam ter sido evitados (...) também nestes casos terá sido frustrada a chance de evitar um dano que efetivamente veio a ocorrer.

As diferenças entre a situação de perda de chance pela quebra de um dever de informar e a perda da chance de evitar um prejuízo efetivamente acontecido prendem-se com o fato de a chance, na primeira, estar ligada a um fato do próprio lesado (...). (...) a chance está com o próprio interessado."

Dallegrave Neto (2004, p. 55) entende que:

"A indenização decorrente da quebra das tratativas é integral (...), porém não atende ao interesse do suposto contrato positivo e válido, vez que não se trata de indenizar o valor total do prejuízo oriundo das sucessivas prestações havidas caso a execução do contrato fosse ultimada. Ao contrário, a reparação do dano pré-contratual atende aos interesses negativos, o que vale dizer: as despesas e prejuízos relativos à frustração da formação do contrato.

(...)

Como se vê, por interesse contratual positivo, abrangem-se todas as consequências da ineficácia de um contrato supostamente válido, enquanto que por interesse contratual negativo se entende o prejuizo com as despesas e a oportunidade imediata que deixou de se ultimar (perda de uma chance) em face da frustrada quebra ou vício do contrato por uma das partes (perda de uma chance)."

A indenização na perda de uma chance sempre será na totalidade do dano, porém pode divergir do dano final, pois ou a eliminação da oportunidade é considerada como um dano em si, ou ela se confunde com parte do prejuízo realmente sofrido, mas condicionado ao alcance da probabilidade da conduta do réu de ter levado a esta lesão, sendo então a indenização sempre menor da vantagem que se visava.

$\mathrm{Na}$ fase pré-contratual há, em decorrência do já abordado princípio da boa-fé objetiva, o dever de informar o trabalhador e se, em consequência da violação deste dever, houver a perda de uma chance da vítima de atingir um be- 
nefício, cabível é a reparação do dano sofrido, quando, por exemplo, o sujeito deixa de negociar com outro empregador, pois compreendeu aquela proposta como mais vantajosa e na verdade não o era.

Assim sendo, nem todo dano ocorrido na fase pré-contratual pode ser considerado como perda de uma chance, mas somente aqueles relacionados à grande probabilidade de atingir um resultado benéfico ou de evitar um prejuízo, o que, no âmbito das relações de emprego, será a contratação ou não do trabalhador - quando, por exemplo, o sujeito deixou de participar de outras entrevistas de emprego diante de promessa de contratação do empregador, mas este não o contrata ou o faz em cargo com piores condições do que a proposta, piorando o estado anterior do trabalhador.

Acertado é o comentário sobre a decisão do TRT da 1. ${ }^{a}$ Região colocado por Sônia Mascaro Nascimento (2012) que afirma que a situação mais corriqueira de perda de uma chance na Justiça do Trabalho consiste na promessa de emprego e "havendo promessa de emprego, forma-se um pré-contrato entre empresa e empregado que, mesmo sem ter sido firmado nenhum contrato formal, vincula as partes e gera obrigações entre elas", ao avaliar a seguinte ementa:

"Recurso ordinário. Expectativa real de contratação. Perda de uma chance. Dano moral e material. Indenização. Devida. A responsabilidade trabalhista não esta adstrita à execução propriamente dita do contrato de trabalho, mas alcança, ainda, a fase das negociações pré-contratuais, bem assim questões pós-contratuais, em consonância aos postulados de probidade, ética e boa-fé objetiva (art. 422 do CC/2002), bem assim com os princípios fundamentais da valorização do trabalho e da dignidade da pessoa humana (art. 1. ${ }^{\circ}$, IV e III, respectivamente). Portanto, as tratativas preliminares que antecedem a contratação formal do trabalhador caracterizam a formação de um pré-contrato de trabalho, que envolve obrigações recíprocas e pressupõe o respeito aos princípios de lealdade e de boa-fé. Portanto, à luz da teoria da perda de uma chance que se fundamenta na probabilidade de que haveria o ganho e a certeza de que a perda indevida da vantagem resultou um prejuízo, o não cumprimento de obrigação pré-contratual que obsta a possibilidade de resultado positivo ao trabalhador, constitui inegável dano, moral e material, a ensejar o pagamento de indenizações correspondentes. Recurso da reclamada a que se nega provimento" (TRT 1. a Região, RO, 0122200-80.2009.5.01.0247, rel. Paulo Marcelo de Miranda Serrano, DEJ 06.10.2011).

Na mesma linha, a 2. ${ }^{a}$ Turma do TST decidiu (nos autos RR 3590053.2009.5.12.0007, j. 27.04.2011, DEJT 06.05.2011), com o Min. rel. Guilherme Augusto Caputo Bastos, que da frustração por culpa da empresa das negociações preliminares que geram esperanças motivadas de uma provável 
contratação advém direito à indenização, mesmo que não mencione expressamente a teoria da perda de uma chance, nos termos do acórdão:

"1. Danos morais. Comprovação de abalo emocional. Inexigibilidade. Suficiência da demonstração da situação fática.

O E. Tribunal Regional julgou procedente a pretensão do reclamante que requereu indenização por danos morais em razão de ter tido frustrada sua expectativa de contratação, não obstante todas as tratativas da empresa. Entendeu, ainda, que a ocorrência do dano moral prescindiria de comprovação do abalo sofrido. (...)

Em verdade, a E. Corte Regional concluiu que o abalo sofrido (o prejuízo indenizável) é que prescindiria de prova e não a circunstância de fato ocorrida. Esta, inclusive, foi adequadamente comprovada, a saber, a grande expectativa gerada pela reclamada no que toca à sua contratação do reclamante e a inesperada quebra dessa expectativa. (...)

Ao exigir a realização de exame admissional e reter a CTPS do autor por 16 dias, fato confessado pelo preposto da ré (...), a empresa induz grande expectativa de contratação ao candidato. Quando repentinamente deixa de realizar o contrato em virtude das dificuldades de mercado, a empresa quebra um dever inerente à boa-fé negocial (...)."

Isto é, eventuais despesas que o empregador exigiu para a contratação, que foi frustrada por sua culpa, serão analisadas sob outro foco, pois não se trata de chance perdida, mas violação frontal ao princípio da boa-fé na fase pré-contratual. A perda de uma chance na responsabilidade pré-contratual nas relações de emprego apenas ocorrerá quando o trabalhador evidentemente tinha uma possibilidade real e séria, analisada via princípio da razoabilidade pelo juiz, de concretizar um acordo com o empregador e este a eliminou, total ou parcialmente, por motivos injustificados que fogem da autonomia privada e liberdade contratual circunscritas pela boa-fé e função social do contrato.

\section{CONCLUSÃO}

A teoria da perda de uma chance consiste em uma abordagem relativamente nova no Direito brasileiro, que carece de uma maior atenção pelos magistrados e pelos estudiosos, visto que a chance, quando séria e real, possui um valor patrimonial que, quando eliminada pela conduta do ofensor, gera o direito a sua reparação.

A aludida construção pode ter natureza jurídica de dano autônomo ou de causalidade parcial, de acordo com os efeitos da intervenção no processo aleatório, quer dizer, se a interrupção da marcha causal foi de tal modo que eli- 
minou toda e qualquer chance de se chegar ao resultado esperado, a perda da chance será considerada como um dano por si, enquanto se ainda prevaleceu algumas chances de se chegar ao benefício, mas o dano final foi concretizado, o nexo causal será avaliado como parcial, se fundamentando na relação de probabilidade.

A responsabilidade pré-contratual nas relações de emprego exige o recurso aos princípios que regem os contratos no Direito Civil, com as devidas adaptações e com base na subsidiariedade típica das relações de trabalho. Neste sentido, à fase pré-contratual se aplica o princípio da boa-fé objetiva, que pressupõe a condução das negociações preliminares com lealdade, colaboração, proteção e informação entre as partes, deveres a serem observados principalmente na esfera trabalhista, aonde o trabalhador é hipossuficiente e carece de maior proteção do ordenamento jurídico.

O princípio da boa-fé proíbe o empregador de criar falsas expectativas no trabalhador, fomentando a impressão de que ele será contratado, o que o leva a realizar despesas, ignorar outras oportunidades e, assim, o prejudica, não podendo procrastinar as tratativas se não tem interesse em pactuar.

Assim, danos decorrentes desta esperança em ser contratado, motivado e provado pelo comportamento concreto do empresário, serão indenizáveis em algumas hipóteses, seja moral ou material, como em caso de um comportamento discriminatório do empregador excluir o trabalhador do processo seletivo, ou dele reter a carteira de trabalho e prometer a vaga e posteriormente não contratar o candidato, mesmo após criar estas falsas expectativas de contratação.

A perda de uma chance na fase pré-contratual dá-se justamente quando o trabalhador, pela situação fática, tem como certo que será empregado e, por causa disto, perde uma oportunidade de melhorar o seu estado. Esta eliminação da chance pode ocorrer pela não efetuação do acordo após, por exemplo, uma promessa de contratação, ou até pelo indivíduo deixar de participar de outros processos seletivos em ofertas de emprego que antes eram menos vantajosas, mas que, pelo pactuado com o empregador, passaram a ser mais atrativas, pois o que foi negociado preliminarmente não foi cumprido no contrato de fato.

Importa que a perda de uma chance se caracteriza como um meio de interpretar a eliminação de oportunidades oriunda da conduta do empregador que não age de acordo com o princípio da boa-fé, pois esta chance tem um valor e faz parte do patrimônio jurídico do trabalhador, não podendo ser violado, sob a escusa retórica da liberdade negocial e autonomia das relações privadas, porque o empresário deve, em todas as fases do contrato, informar e agir com lealdade e proteção da parte hipossuficiente. 


\section{REFERÊNCIAS BIBLIOGRÁFICAS}

Azevedo, Antonio Junqueira de. Responsabilidade pré-contratual no Código de Defesa do Consumidor. Revista de Direito do Consumidor. vol. 18. p. 23. São Paulo: Ed. RT, abr.-jun. 1996.

Dallegrave Neto, José Afonso. Responsabilidade civil pré e pós-contratual no direito do trabalho. Revista TRT 9. ${ }^{a}$ Região. ano 29. n. 53. p. 53-70. Curitiba: Serviço de biblioteca e jurisprudência, jul.-dez. 2004.

Delgado, Mauricio Godinho. Curso de direito do trabalho. 7. ed. São Paulo: Ed. LTr, 2008.

Dias, Sérgio Novais. Responsabilidade civil do advogado na perda de uma chance. São Paulo: Ed. LTr, 1999.

Dinız, Maria Helena. Curso de direito civil brasileiro. 24. ed. São Paulo: Saraiva, 2008. 3. vol.

Nascimento, Sônia Mascaro. Indenização pela perda de uma chance. Disponível em: [www.amaurimascaronascimento.com.br/index. php?option=com_content \&view=article \&id=274:5-indenizacao-pela-perda-de-uma-chance\&catid=68:decisoes-comentadas\&Itemid=206]. Acesso em: 09.06.2012.

Noronha, Fernando. Direito das obrigações: fundamentos do direito das obrigações. São Paulo: Saraiva, 2003. vol. 1.

SAVI, Sérgio. Responsabilidade civil por perda de uma chance. 2. ed. São Paulo: Atlas, 2009.

Silva, Hebe Mara Sá. Danos morais na fase pré-contratual das relações individuais trabalhistas. Anais do XVII Encontro Preparatório para o Congresso Nacional do Conpedi. Salvador, 2008. p. 5189-5208. Disponível em: [http:// conpedi.org.br/manaus/arquivos/anais/salvador/Integra.pdf]. Acesso em: 09.06.2012.

Silva, Leda Maria Messias; Bezerra, Christiane Singh. A responsabilidade pré-contratual e pós-contratual com vistas ao direito de personalidade nas relações de trabalho. Anais do XVII Congresso Nacional do Conpedi. Brasília, 2008. p. 6639-6661. Disponível em: [http://conpedi.org.br/manaus/arquivos/anais/ brasilia/integra.pdf]. Acesso em: 09.06.2012. Silva, Rafael Peteffi da. Responsabilidade civil pela perda de uma chance. 2. ed. São Paulo: Atlas, 2009.

Vicente, Dário Manuel Lentz de Moura. A responsabilidade pré-contratual no Código Civil Brasileiro de 2002. Revista CEJ. n. 25. p. 34-41. Brasília: Senado, abr.-jun. 2004. 


\section{Pesouisas do Editorial}

\section{Veja também Doutrina}

- Responsabilidade por perda de chances, de Fernando Noronha - RDPriv 23/28;

- A responsabilidade civil pela perda de uma chance: a técnica na jurisprudência francesa, de Daniel Amaral Carnaúba - RT 922/139;

- A responsabilidade civil pela perda de uma chance no direito brasileiro, de Gilberto Andreassa Junior - RDPriv 40/177; e

- A teoria da perda de uma chance e sua aplicação no direito brasileiro, de Glenda Gonçalves Gondim - RT 922/611.

\section{Veja também Jurisprudência}

- Perda de uma chance por expectativa real de contratação: JRP\2011\4126. Disponivel em: [www.revistadostribunais.com.br]. 